NEW WELDABIE HHGH STRENGTH ALDMINOM ALLOYS FOR CRYOGENIC SERVICE

by

H. Y. Hunsicker ${ }^{(1)}$ and J. H. Hess $(2)$
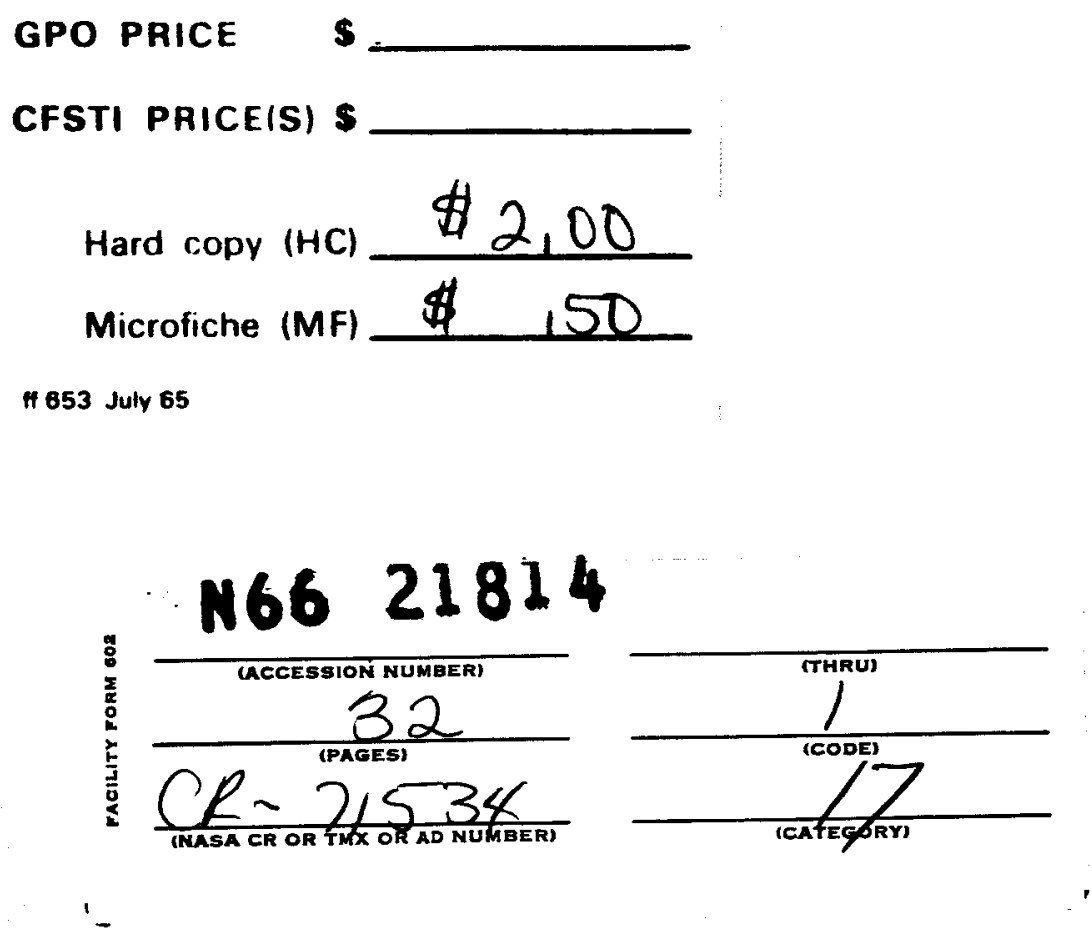

(1) Physical Metallurgy Division, Alcoa Research Laboratories

(2) Materials Division, Propulsion and Vehlcle Engineering Laboratory, Marshall Space Flight Center, NASA 
It is apparent that one of the most important of the basic criteria for structural materials for use in space vehicles is a maximum strongth/weight ratio consistent with the additional requirements of toughness, fabricabllity and compatibility with manufacturing, storege and service envirommonts. Ifquid-propellant vehioles of the current generation, culminating with the mighty S-IC booster stage of the Saturn V, are constructed principally of aluminm alloys. Weldability and low temperature notch insensitivity requirements greatly influence alloy selection for fuel and oxidizer tankage. Vartous vehicles have employod Al- Kg alloys, 5456 and 5083 (Saturn I), the Al-Cu-KB alloy 2014 (Titan II and S-II socond stage and S-IVB third stage of Saturn V) and tho Al-Cu alloy 2219 (S-IC booster stage of Saturn V). The highest strength veldable alloys commercially avallable are 2014 and 2219, and in the tempers used these provide yleld strengths in the 50 to $60 \mathrm{ks} 1$ range and ultimate tensile strengths of 60 to $70 \mathrm{ks} 1 \mathrm{with}$ veld joint efficiencies of $60-80 \%$ as-wolded.

The higher strength Al-Zn-Hg-Cu alloys 7075 and 7079 are considerably less veldable and have rather poor aryogentc temperature notch-toughness so that they are regarded as unsuitable for oxtdizer and fuel tankage. They find extensive use, however, in thrust and interstage structures that are assembled with fasteners as in conventional aircraft construction. Recently developed alloys of the Al-Zn-Mg (Cu-free) type, 7039, $X 7106$ and $X 7004$ are readily weldable and develop potent1ally 
useful combinations of tensile properties, cryogenic toughness and weld strength but do not meet the high strength requirements considered essential for improved future vehicles.

Recognizing that further advances in efficiency and increased range or pay-load capability of liquid-propellant boosters are dependent to a large degree upon the avaljability of even higher strengti materials, the Varshall Space Flight Conter (USFO) of the National Aeronautios and Space Administration (IASA) Initiated a contract (NAS 8-5452) for the development of a higher strength weldable aluminum alloy with good cryogenic toughness. The goal of the program was an alloy that could be produced as plate with a room temperature ultimate tensile strength approaching $75 \mathrm{ks}$, Jield strength of $65 \mathrm{kal}$ and elongation of 15\% (later lowered to 10\%). A ratio of notched to unnotched tensile strengths (notched/unnotched tens1le ratio) of 1.0 at room temperature and 0.9 at -423 F was desired. Good weldability with a room temperature weld efficienoy of $80 \%$ and an es-welded notched/unnotohed tensile ratio at $-423 \mathrm{~F}$ of 0.85 vere additional objectives. Another requirement was good resistance to corrosion and atresscorrosion oracking in industrial and seacoest environments.

\section{Researah Program}

The preliminary survey to ascertain the most promising avenues for development suggested an interesting approach based on the discovery by Nook ${ }^{(1)}$ in the early 1930's that very amall aduitions of $S n$, $C \tilde{d}$ or In to $A I-C u$ alloys accelerated elevated tomperature preolpitation and Increased strength. Alloy 273, besed 
on this effect, was produced on a limited scale starting in 1932. Although this alloy was successfully used in several applications, it was discontinued because of disinterest at that time among structural engineers and atrcraft designers in materials with elongations less then 18 to 20\%. The principle appeared applicable to alloy 2219 as a means of obtaining a higher strength weldable composition.

It was also concluded that low-Cu alloys of the Al- $\mathrm{Zn}-\mathrm{Hg}$ type with the addition of $\mathrm{Zr}$, which had been found to Improve both weldabllity and cryogentc toughness ${ }^{(2)}$, offered promise of meeting the program objectives. Al-MB alloys were consldered to have insufficlent potential for increased strength to merit more then very cursory experimental work, and the possibility of Increasing the strength of $\mathrm{Al}-\mathrm{Mg}_{2} \mathrm{SI}$ alloys to the desired range was consldered so remote that no development effort on them was recommended.

In the inftial experimental program 30 alloy compositions were cast and fabricated as sheet. Supplementary survey programs were conducted with additional compositions suggested by the infitial results. The alloys were first tested in several tempers produced by established heat treating procedures, and a closely integrated program to optimize heat treating conditions for the more promising compositions wes conducted concurrently. Screening evaluations were based on tensile and notched-tens1le properties at room temperature and $-320 \mathrm{~F}$.

More extensive evaluation of the most promising campositions Involved laboratory fabrication of 0.525 and $1.0^{\prime \prime}$ plate and 
performance of tensile and notched-tensile tests at R.T., -112, -320 and $-423 \mathrm{~F}$. Tests vere made to evaluate weldability and MIG and TIG weld properties in both as-welded and post-weld aged conditions. Corrosion and stress-corrosion tests of parent plate and weldments were conducted in an accelerated exposure by alternate immersion in $3.5 \% \mathrm{NaCl}$ solution, and longer time tests were infliated in Industrial and seacoest exposures. The two alloys selected es having the greatest promise were subsequently mill-fabricated in a range of gages to a maximum thickness of 2-3/8" and subjected to the complete testing progrem. Because of some deviations in the heat treating response of these fullscale products compared with that of the smaller laboratory-scale. sections, additional heat treating development was required.

\section{Results}

Al-Zn-Kg Alloys. As background for the selection of the condidate Al-Zn-Mg type alloy and to exemplify the kind of information obtained in the experimental survey progrem, data relating strength and notch toughness for the series of Al-Zn-MB alloys are summarlzed in Fis. 1. The dashed curves are 1so-yleld strength lines indicating the different combinations of $\mathrm{Zn}$ and $\mathrm{Mg}$ contents that produce Fleld strengths of 55,60,65,70 and $75 \mathrm{ks1}$. The effects of composition on the $-320 \mathrm{~F}$ notched/unnotched tensile ratios are shown by the solid curves. The heavy solld ourve extending from the lower-left toward center-right in the diagram is the approximate loc1 of compositions having the most favorable combinations of strength. and toughness. The tentative $\mathrm{Zn}$ and $\mathrm{Mg}$ limits for the selected candidate alloy are indicated in Fig. 1 by the small rectangle. 
In considering the $-320 \mathrm{~F}$ notched/unnotched tensile ratios shown In Fig. I in relation to those listed later in the paper for the alloy evolved from this work, It may be noted that the Fig. I values are considerably lower. There are two reasons for this. First, the survey program alloys for which the data are plotted did not contain $\mathrm{Zr}$. Second, notched/unnotched tens1le rat10 velues for edge-notched she日t specimens are considerably lower than those determined with olrcumferentially-notched round specimens. The graph further 1llustrates the well-known fact that, In general, toughness declines with increasing strength. The formilation of alloys with increasing solute content, $\mathrm{Zn}$ and Mg, permits attainment of strengths bejond the establishod gosis but only at a considerable sacrifice in toughness as well as reduced fabricability and deterioriation of weldablitity and resistance to stress-corrosion cracking.

It has been known for some time that Al-Zn-Mg alloys characteristically show a more rapld increase in notch sensitivity with decreasing temperature than is observed for Al-Cu or Al-MB type alloys. This temperature effect appears to be considerably modified by the addition of a amall percentage of $\operatorname{Zr}(0.12 \%$, nominal) and 1s reflected in the data 1llustrated by Fig. 2. These data again waro obtainod with smooth and odge-notched sheet tensile specimens so that notched/unnotched tensile ratio values are lower than those reported for round specimens. A range of compositions, heat treatments and varlations in fabrication is represented and accounts for the 
relatively broad bands for the two alloy groups.

Among heat treating varlables investigated, elevated temperature aging had the most significant effect on the machanical properties, although rapid quenching was shown to favor higher toughnoss for a given yield strength. Rapld quenching, however, has been shown to be less desirable than controlled slower quenching with regard to the resistance to stress-corrosion cracking. The nature of the influence of various elevated temperature aging practices on combinations of rocm temperature strength and $-320 \mathrm{~F}$ notch toughness is indicated In Fig. 3. In general, strength and toughness for a given alloy bear an inverse relationship to one another with varlations in aging up to and including the maximum strength portions of the aging time-temperature curves. The F1g. 3 data show appreclably higher notched/unnotched tensile ratios than those of Fig. 2 because cyclindricel specimens were employed in testing the 1.0" thick plate that provided the information for Fig. 3. It may be noted that the data shown for the two $\mathrm{zr}$-containing alloys may be considered as representing low and high Mg content versions of the candidate Al-Zn-Mg type alloy selected from the program. Al-Cu Alloys. Inltiel results with sheet showed that additions of $0.3 \% \mathrm{MB}$ or $0.3 \% \mathrm{MB}$ plus $0.3 \% \mathrm{~S} 1$ to alloy 2219 increased strength, the improvement in a T6 temper approximating $7 \mathrm{ks}$ in yleld strength and about $2.5 \mathrm{ks} 1$ in tensile strength. Higher strongths were obiained with an alloy containing $0.2 \% \mathrm{~cd}$, the yleld and tensile strength increments with respect to 2219 being 
about 12 and $8 \mathrm{ksi}$, respectively. The largest strength Improvement was assoclated with an alloy containing additions of $0.18 \% \mathrm{~cd}$ and $0.05 \% \mathrm{Sn}$ which provided tensile and yleld strength increases of about 14 and $9 \mathrm{ks}$. The latter became the focus of attention for the advanced laboratory evaluation in which $0.525^{\prime \prime}$ plate developed room temperature strengths equalling. the objectives of $75 \mathrm{ksi}$ tensile strength and $65 \mathrm{ksl}$ yield strength with an elongation of $9 \%$ and -320 and $-423 \mathrm{~F}$ notched/unnotched tensile ratios exceeding 1.0 .

\section{Candidate Alloys}

These investigations disclosed that selected compositions of both types had sufficient promise of attaining the desired combination of properties to merit continued development effort. After selection of the nominal chemical compositions, additional work was infliated to define appropriate composition limits. The alloys selected were designated X2021 ( $\mathrm{Al}-\mathrm{Cu}$ type) and X7007 (Al-Zn-Mg type), and their nominal compositions and tentative limits are listed in Table 1.

$X 2021$ is a complex composition requiring close control over eleven elements. The basic hardenting is provided by precipitation of a transition Al-Cu phase, the nucleation of which is assisted by the presence of $\mathrm{Cd}$ and Sn. Manganese provides supplementary strengthening and aids in the control of grain size during fabrication. Titanium is an ingot grain refiner and together with $\mathrm{Zr}$ and $V$ minimizes weld cracking. An upper limit $1 \mathrm{~s}$ placed on $\mathrm{Kg}$ content to avold formation of the insoluble $\mathrm{Mg}_{2} \mathrm{Sn}$ phase which Interferes with precipitate nucleation. 
X7007 1s somewhat less complex, but also necessitates control of nine elements. In addition to the basic hardening combination of $\mathrm{Zn}$ and $\mathrm{Mg}$, which confers precipitation hardening of both zone and transition phase types, supplementary elements include $\mathrm{Mn}, \mathrm{Cr}, \mathrm{TI}$ and $\mathrm{Zr}$ for grain control, stress-corrosion benefit and improved weldability. There is evidence that the most favorable cryogenic toughness is obtained with a combination of $\mathrm{Zr}$ and $\mathrm{Cu}$, so that the latter element is currently indicated in the nominal composition.

Heat Treatment. The recommended solution heat treating temperature for X2021 is $980 \mathrm{~F}$, and rapld quenching in cold water is the preferred practice. The aging practice required for products of this alloy that must be stretched or rollerleveled after quenching to straighten or flatten is unlque among those normally used for aluminum alloys. The strain that accompanies stralghtening after quenching alters precipitate nucleation and interferes with strength development unless a moderate pre-aging treatment at elevated temperature is used to establish the precipitate pattern prior to straightening. Th1s spectal sequence of operations for X2021 is 1dentifled by an experimental temper designation, T8E31. The pre-aging is normally limited to about one hour at $300 \mathrm{~F}$ to keep the strength below a level that would make straightening difficult, and the permanent set during straightening is also 1imited. Subsequent aging requires 10 hours at $325 \mathrm{~F}$.

The treatment for X7007 will be of the T6 type with some detalls remaining to be established before selection of the 
preferred practice. A solution temperature of $860 \mathrm{~F}$ is appropriate for this alloy. Some advantage with respect to the resistance to stress-corrosion cracking is expected from controlled moderate-rate quenching. Elevated temperature aging conditions can be adjusted to provide strengths higher than can be attained with $\mathrm{X} 2021-18 \mathrm{E} 31$, but the most attractive compromise between strength and cryogenic toughness appears to be at strength levels comparable with those of the Al-Cu type alloy. Mechanical Properties of Plate. The amount of testing that has been performed on mill-fabricated plate of the new alloys is insufficient to quote typical properties on the besis that is customary with aluminum producers, that 1s, statistically derived values representing many lots and many tests. The data listed in Table 2 have been rounded-off and same judgment applied in resolving minor inconsistencios in certain replicate values. They are considered to be representative of the properties to be expected from the new alloys, and comparisons may be made with the older alloys listed. The strengths of the new alloys at room temperature are about 10 to $15 \%$ higher than those of the high strength weldable alloys developed prior to the contract. H1gher yield strengths are evident for the now alloys at low temperatures also, but the advantage in ultimate tensile strength declines with decreasing temperature. At these increased strength levels the elongation values either remain essent1elly constant with temperatiure (X202I-TOËJI) or decline with decreasing temperature ( $x 7007-16$ type), which contrasts in elther case with the behavior of 2219-T87 and $x 7106-T 6351$. A consistent difference 
In characteristic temperature effects between Al-Cu type alloys (X2021 and 2219) and those of the Al-Zn-Mg type (X7007 and $X 7106)$ may be noted in the notched/unnotched tensile ratio values. The $\mathrm{Al}-\mathrm{Cu}$ alloys show relatively little change in notch toughness with temperature while those of the Al-Zn-Mg type evidence increased notch sensitivity with decreasing temperature. These effects are apparent in the graphical presentation of data for the new alloys, Fis. 4.

The extent to which composition variations within the tentative limits for the two alloys may be expected to affect their mechanical properties may be estimated from the date of Table 3. For each alloy seven compositions were cast and fabricated in the laboratory to 0.525 " plate. Maximum and minimum concentrations of the primary strengthening elements as well as other combinations within the limits were included among the variations. Although the strengths observed with the laboratory-fabricated X2021-T8E31 plate were samewhat lower than those measured on the mill-fabricated product, the varlations in properties with composition were modest. Somewhat greater variation is to be expected within the limits of $\times 7007$, but commercial control with more restrictive composition limits would offer considerable difficulty. Weldability. The relative weld-cracking tendencies of X2021 and $x 7007$ were evaluated employing tests described by Dowd $(3)$. These tests Involve production of tee-joint double-flilet weld specimens w1th both continuous and discontinuous welding procedures. Ratings are based upon extent of cracking observed. 
Comparative weldability ratings for the new alloys are indicated in bar-graph form in Fig. 5 with those of other high strength alloys that have been used for cryogenic weldments. An exception 1s 7075, which is seldom welded, but was included to Indicate the substantial improvement in weldability represented by X7007.

X202I is considered as readily-welded by KIG and TIG processes employlng 2319 filler as are 5456 welded with 5556 or 2219 welded with 2319 . Its rating is definitely superior to that of 2014 welded with 2319 , and little difficulty should be experienced with this new alloy. X7007 is less weldable but is rated as commercially weldable when good control is exercised. This rating is based on the use of an experimental filler which is similar in composition to X7007 but with higher Mg content. A higher weldability rating, comparable with that shown for $\times 7106 / \times 5180$, can be assigned to the combination of $\times 7007$ welded with $\times 5180$ f1ller. The welds, however, have lower strength, and the gain in weldability would have to be equated against the increased weight of additional weld-land relnforcement needed to compensate for the lower strength. A greater frequency of weld cracking was encountered in welding thicker gages of X7007 by the MIIC process then by TIG. As-welded properties obtained by the latter process were appreclably higher, however. Weld Propert1es: Welded panels for dotermining wold properties were radiographed, and those selected for testing exhibited soundness equal to or better than Class II of the Army Bell1st10 Miss1le Agency document ABMA-PD-R-27A: Tens1le tests were 
performed with reduced-section and full-section specimens of the designs shown in Fig. 6. The reduced-section specimens are designed to fracture the weld. The full-section spec1mens, tested without removing the bead, permit fallure to occur elther through or adjacent to the weld, whichever location is weaker. For notched tensile tests the notches $\left(K_{t}=10\right)$ were located in the weld.

Results obtained w1th MIG and TIG welded X2021-T8E3I sheet and plate employing 2319 filler are l1sted in Table 4. The veld properties of the new alloy welded w1th 2319 are not markedly affected by the welding process used and are slightly higher than are obtained with 2219 welded with this f1ller. Post-veld aging increases the tensile strength of the welds with some lowering of elongation values but little effect an notched/unnotched tensile ratios. The ratios, 1.00 to 1.10 at room temperature and 0.87 to 1.02 at $-320 \mathrm{~F}$, were similar to those determined for 2219 welded with 2319. Additional experiments have been conducted with experimental filler compositions designed to increase the strength of welds made with X2021 plate. Although these tests have not progressed to the point at which an Improved f1ller composition can be recommended, significantly higher weld strengths have been achieved.

The as-welded and post-weld aged strengths of X7007 welded with the experimental filler are the highest that have been observed with welded aluminum alloys that have not been post-weld solution heat treated. The notched/unnotched tensile 
ratios are very good at room temperature $(\sim 1.10)$, but because of the more pronounced temperature effect with this type alloy are lowered to around 0.80 at $-320 \mathrm{~F}$. To demonstrate the degree of variability in weld properties resulting from parent plate composition variations within the tentative X7007 I1mits, average, minimum and maximum data for six laboratory-fabricated lots are tabulated in Table 4. The variations are considered to be modest, and indicate that with good control a high degree of unfformity in weld strength can be maintained.

A comparison of weld ultimate tensile strengths for the new alloys with those of other weldable aluminum alloys used at cryogenic temperatures is shown in Fig. 7 .

Corrosion Characteristics. A comprehensive program of corrosion and stress-corrosion tests of plate and weldments is in progress w1th both accelerated and natural exposures. It is too early, however, to completely define the characteristics of these alloys and establish quantitative ratings. Nelther alloy is expected to exhibit the very high resistance to general corrosion associated with Al-Mg alloys such as 5083 and 5456, although X7007 should approach this degres of resistance. Alloy X2021 is expected to be comparable w1th 2219 and 2014.

Preliminary evidence from accelerated tests indicates that X2021-I6E31 has a high order of resistance to stresscorrosion cracking at high stress levels. Although it may be somowhat infertor to 2219 in artificially agod tempers, it is superior to 2014-M6 which has no record of stress-corrosion cracking in cryogenic service. Alloy X7007 in the T6 type 
tempers hes good resistance to stress-corrosion cracking in the longltudinal and long transverse directions. When high tensile stresses are applied in the short transverse direction, stress-corrosion cracking may occur. In this respect, the alloy is not expected to show a marked departure fram the behavior of related alloys such as X7106 and 7039 in the $T 6$ temper.

\section{SUMMARY}

Two new aluminum alloys have been developed as high strength candidates for cryogenic structure and tankage applications with particular reference to the requirements of l1quid propellant space boosters. Designated X2021 (Al-Cu typo) and X7007 (Al-Zn-Mg type), these alloys are suitable for fabrication of plate and other wrought products and w11l provide strengths 10-15\% higher than present camercial weldablo aluminum alloys with good toughness at cryogentc temperatures. The alloys have good weldability, and high weld properties can be attained. In resistance to corrosion and stress-corrosion cracking they compare favorably with other high strength aluminum alloys now used for cryogentc service.

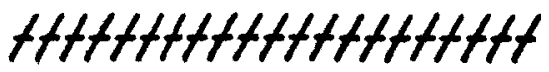

This development was conducted by Alcon Research Laboratories for the Marshall Space Flight Center of the National Aeronautics and Space Administration under Contract Number NAS 8-5452. 


\section{REFIERENCES}

1. J. A. Nock, Jr., U.S. Patents 2,063,942; 2,083,576; 2,225,925; 2,304,949.

2. W. A. Anderson, J. G. Kaufman and J. E. Kane, "Kotoh Sensitivity of Aluminum-Zine-Hagnesium Ailoys at Cryogentc Temperatures," Advances in Cryogentc Enginooring, 2, 104-111 (August 19-21, 1963).

3. J. D. Dowd, "Weld Cracking of Aluminum Ailoys," The Wolding Journal, 31, 448-8 to 456-s (1952).

4. J. E. Compbell, "Aluminum Alloys for Cryogenic Service," Materials Research and Standards, 4, $540-548$ (1964). 
Table 1

Nominal Compositions and Tentative Iimits for Aluminum Alloys X2021 and $\times 7007$

\begin{tabular}{|c|c|c|c|c|c|c|}
\hline \multirow[t]{2}{*}{ Alloy No. } & \multicolumn{3}{|c|}{ X2021 } & \multicolumn{3}{|c|}{17007} \\
\hline & Hominal & Min. & Max. & Nominal & Min. & Max. \\
\hline S1 & - & - & 0.20 & - & & \\
\hline Fe & - & - & 0.30 & - & T & 0.40 \\
\hline $\mathrm{Cu}$ & 6.3 & 5.8 & 6.8 & 0.10 & - & 0.25 \\
\hline Mn & 0.3 & 0.20 & 0.40 & 0.2 & - & 0.40 \\
\hline M8 & - & - & 0.02 & 1.8 & 1.4 & 2.2 \\
\hline Cr & - & - & - & 0.12 & 0.05 & 0.25 \\
\hline $\mathbf{z n}$ & - & - & 0.10 & 6.5 & 6.0 & 7.0 \\
\hline T1 & 0.06 & 0.02 & 0.10 & 0.04 & 0.01 & 0.06 \\
\hline $\mathrm{Zr}$ & 0.18 & 0.10 & 0.25 & 0.12 & 0.05 & 0.25 \\
\hline $\mathbf{v}$ & 0.10 & 0.05 & 0.15 & - & - & - \\
\hline $\mathrm{cd}$ & 0.15 & 0.05 & 0.20 & - & - & - \\
\hline Sn & 0.05 & 0.03 & 0.08 & - & - & - \\
\hline Others, each & - & - & 0.05 & - & - & 0.05 \\
\hline Others, total & - & - & 0.15 & - & - & 0.15 \\
\hline
\end{tabular}




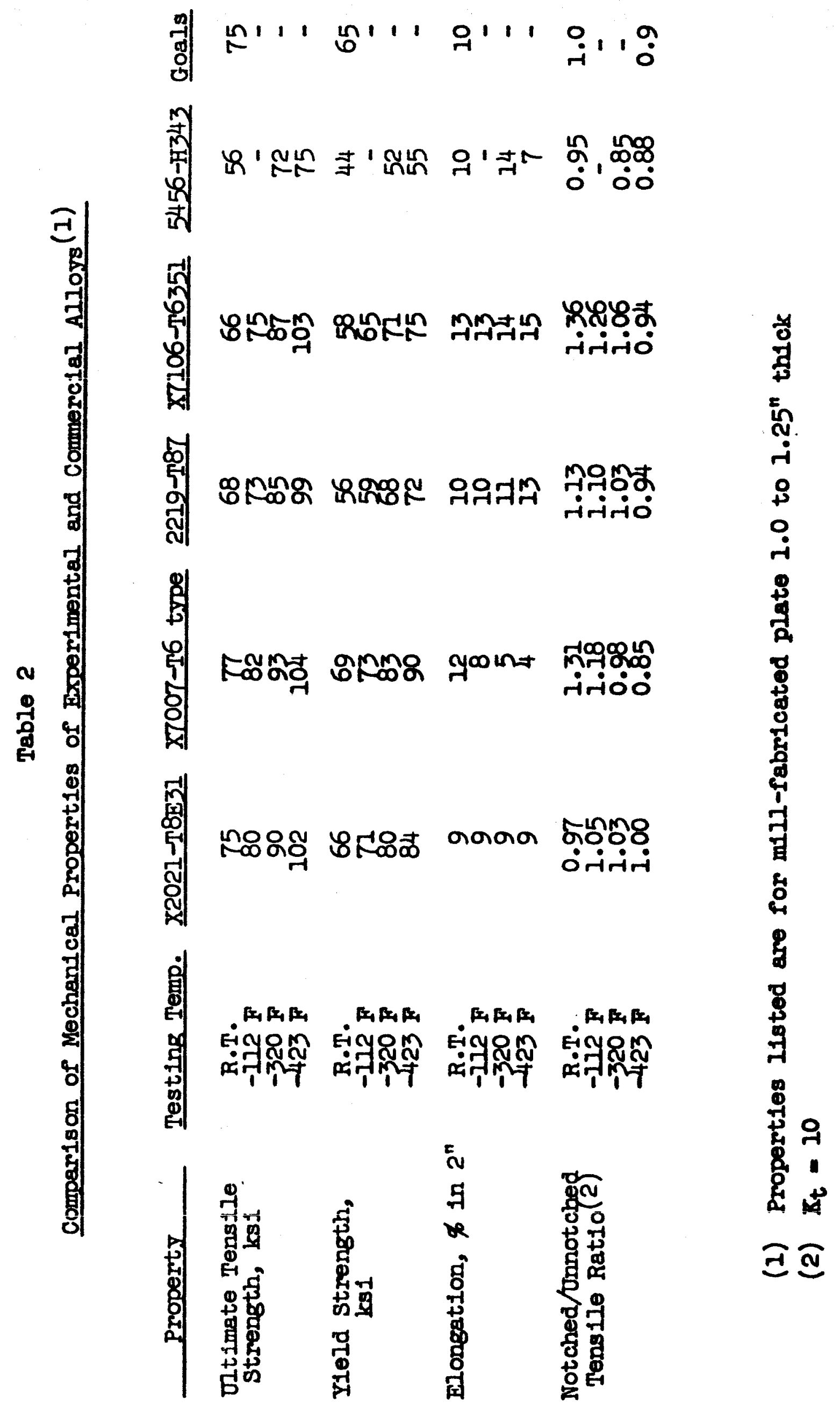




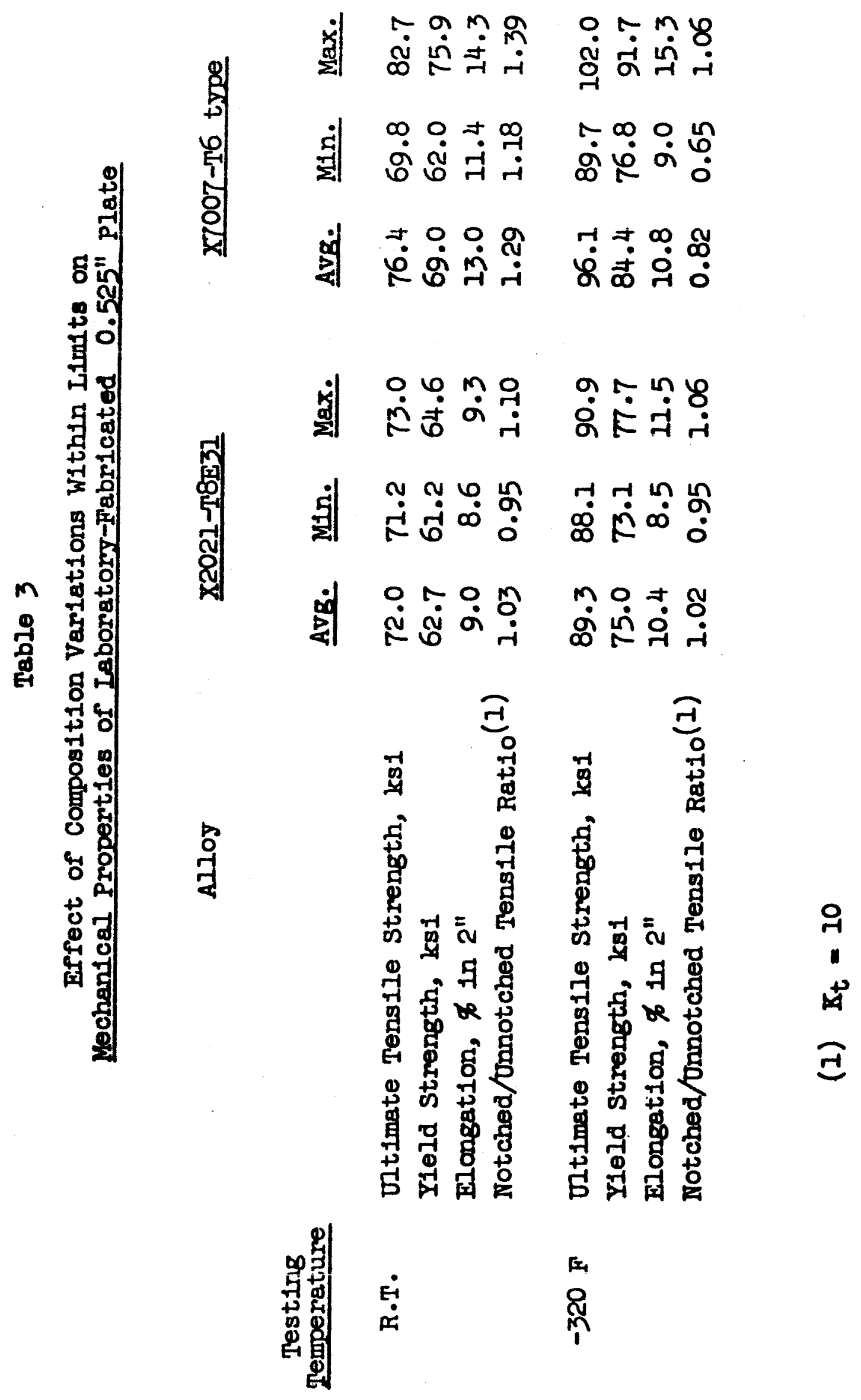




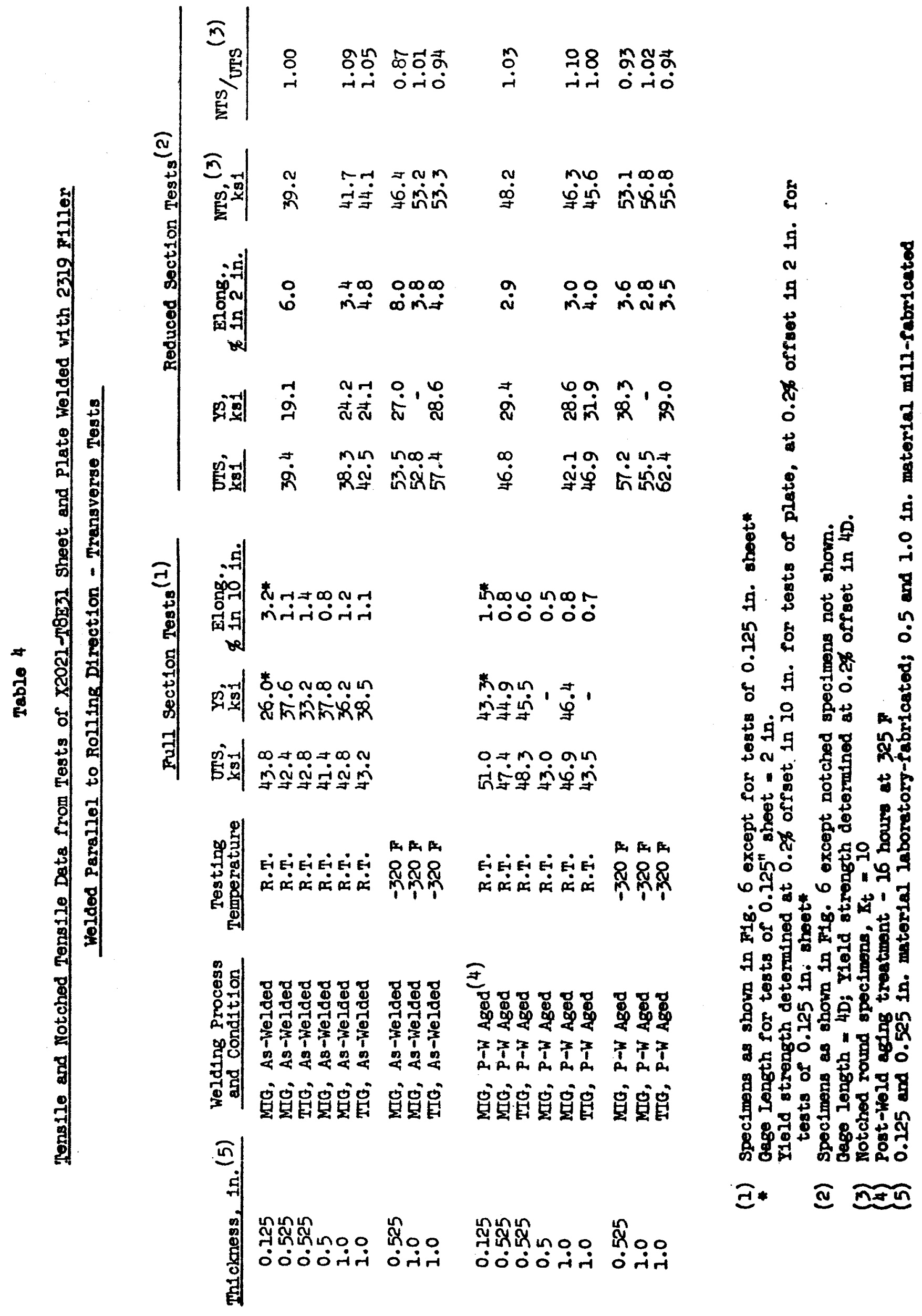




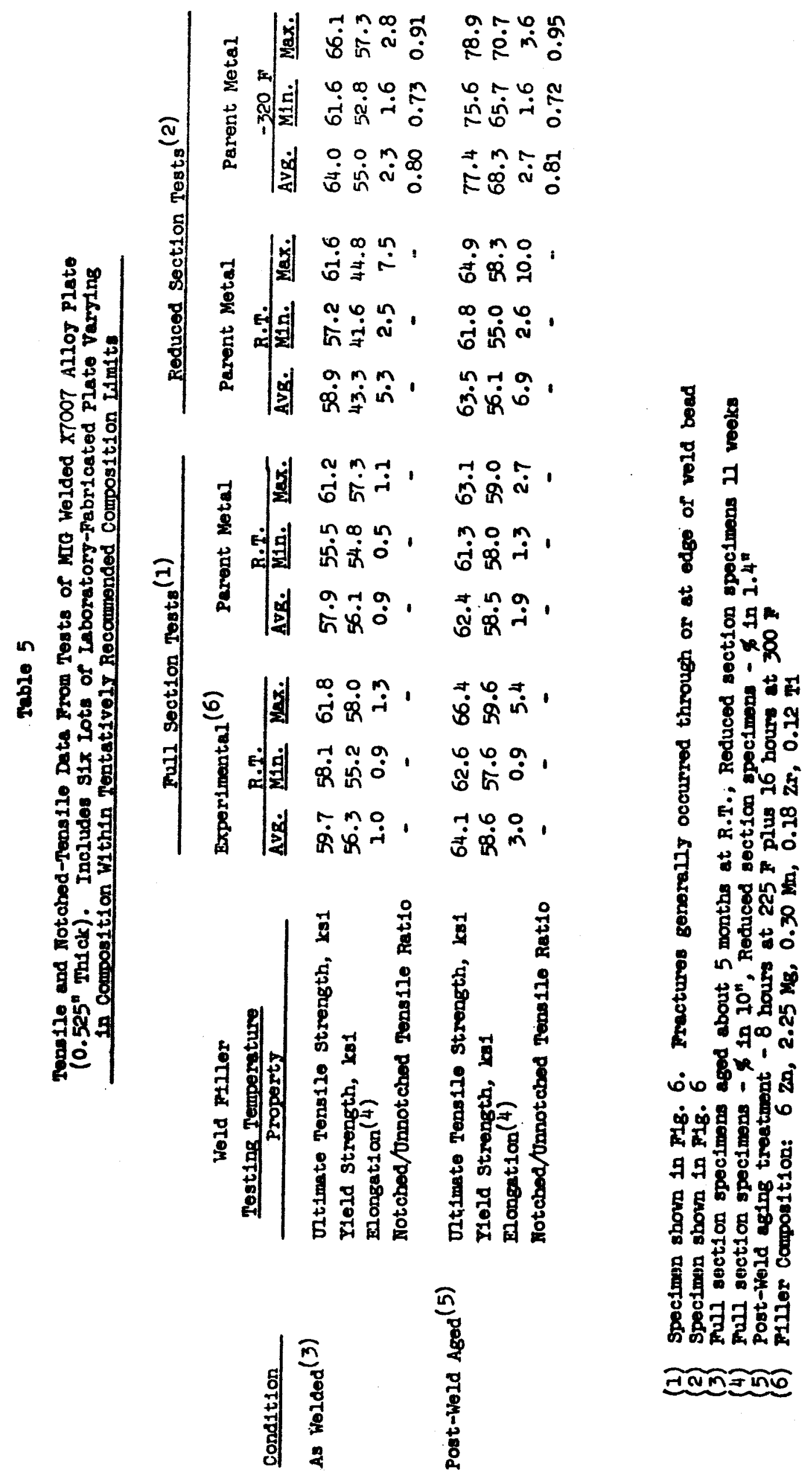



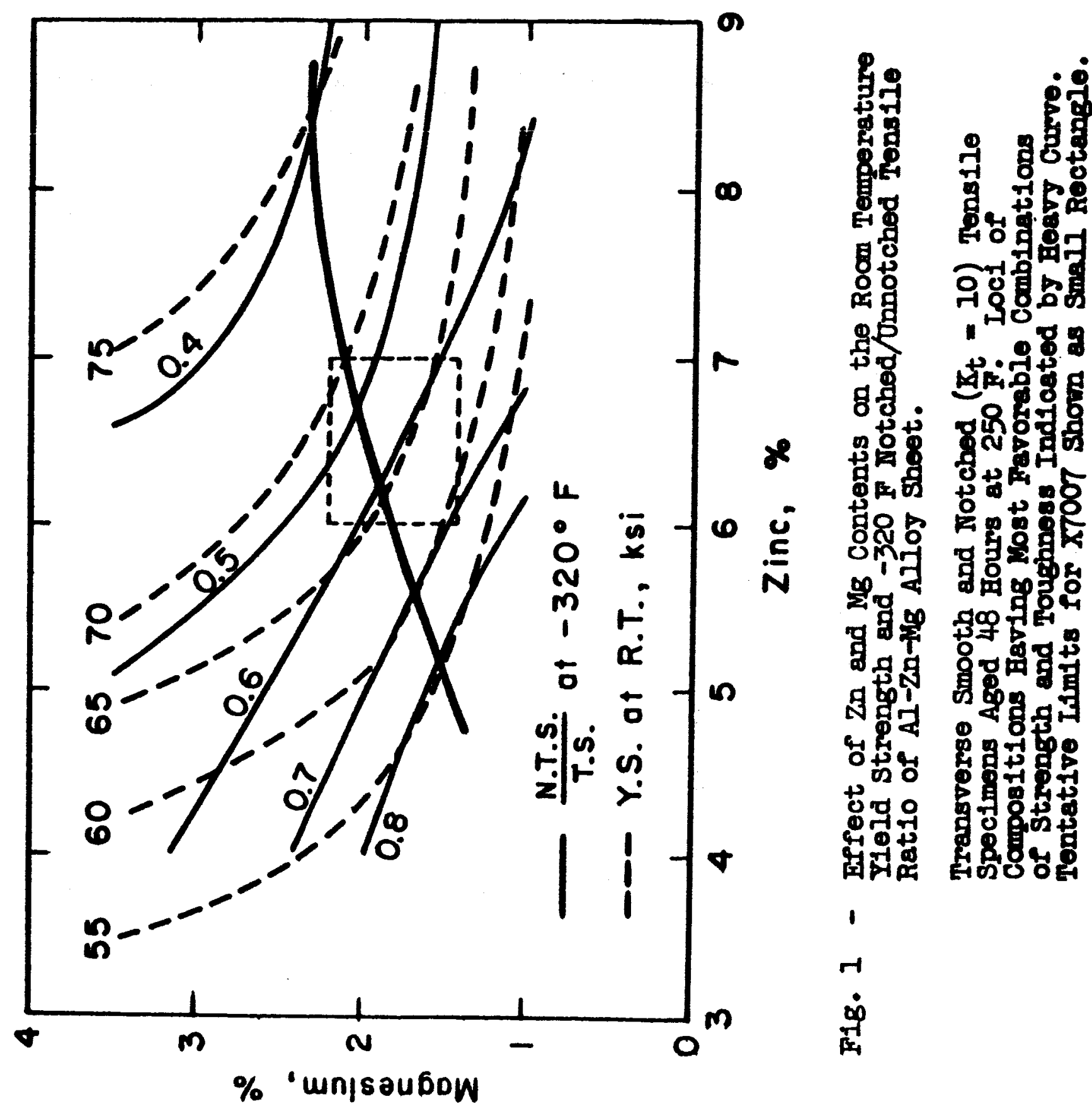

1
rif
P 




F18. 2 - Comparison of Room Temperature Y1eld Strength and $-320 \mathrm{~F}$ Notchod/tunnotchod Tensile Rat1os of Al-Zn-KB Alloy sheot With and Without Zr Addition.

Alloys Contained 5.5 to $7.0 \% \mathrm{Zn}$ and 1.25 to $2.25 \% \mathrm{Mg}$. Data are Included for Several Varletions of Heat Treatment and are from Transverse Smooth and Notchod $\left(K_{t}=10\right)$ Sheet Specimens. 


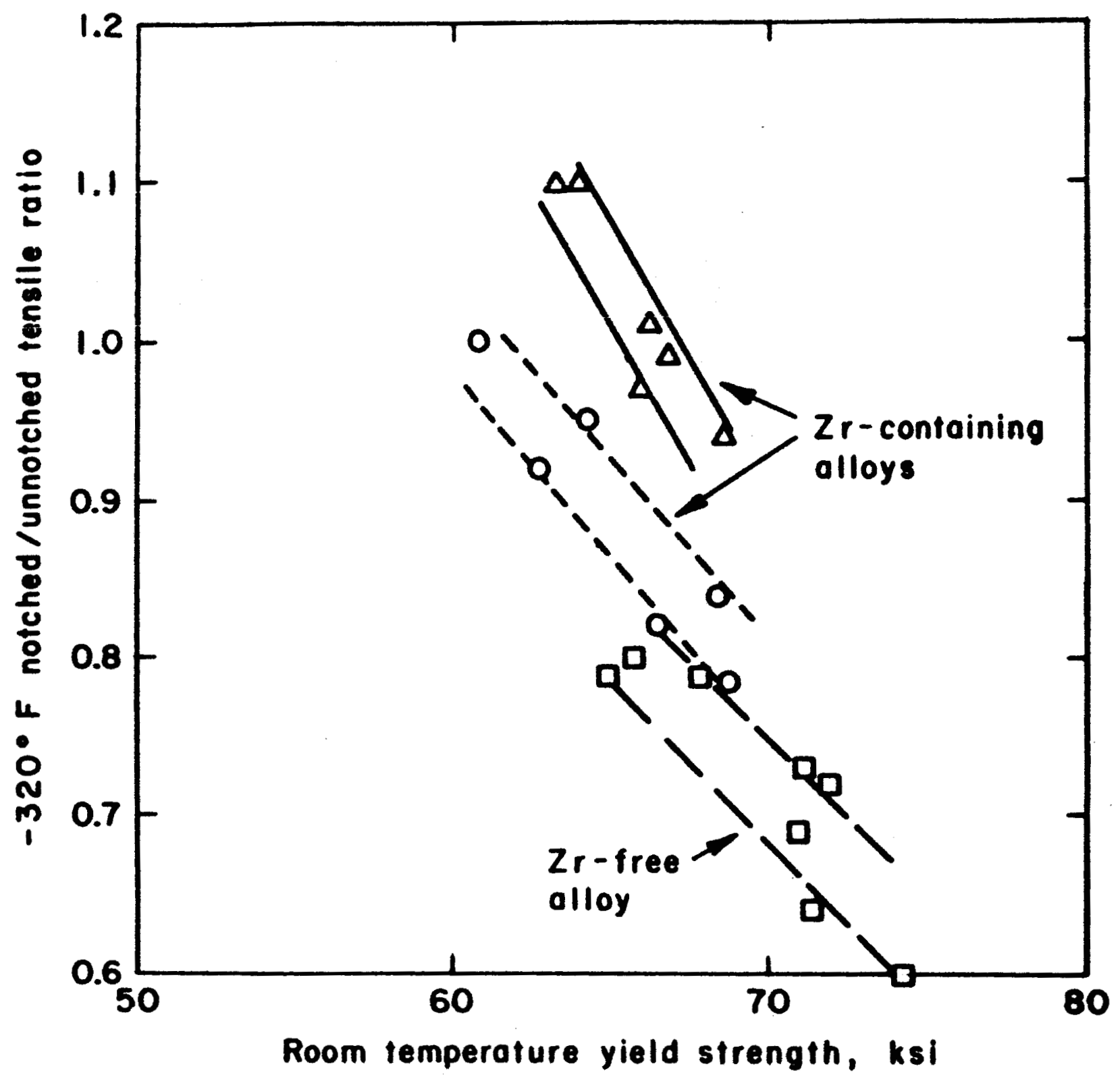

F18. 3 - Effect of Varlations in Elevated Temperature Aging Conditions on Combinations of Room Temperature Yiold Strength and $-320 \mathrm{~F}$ Toughness Determined for 1.0" Plate of Three Al-Zn-kg Typo Alloys. Aging Time and Temperature Ranges: 4 to 168 Hours, 225 to $300 \mathrm{~F}$. Cylindricel Smooth and Notched $\left(K_{t}=10\right)$ Speoimens,
$\underline{\text { cu }}$
Fe
$\underline{\text { S1 }}$
Mn
Zn
$\underline{\mathrm{Cr}}$
$\underline{\mathbf{Z r}}$
$T 1$
$\begin{array}{lll}\Delta & .12 & .18 \\ 0 & .12 & .16\end{array}$
.09
.21 1.64
6.51
.13
.10
.01
$\begin{array}{lll}0.11 & .16\end{array}$
$.09 \quad .21$
2.22
6.20
.13
.10
.01
$.20 \quad 2.65$
6.18
.12
.00
.01 


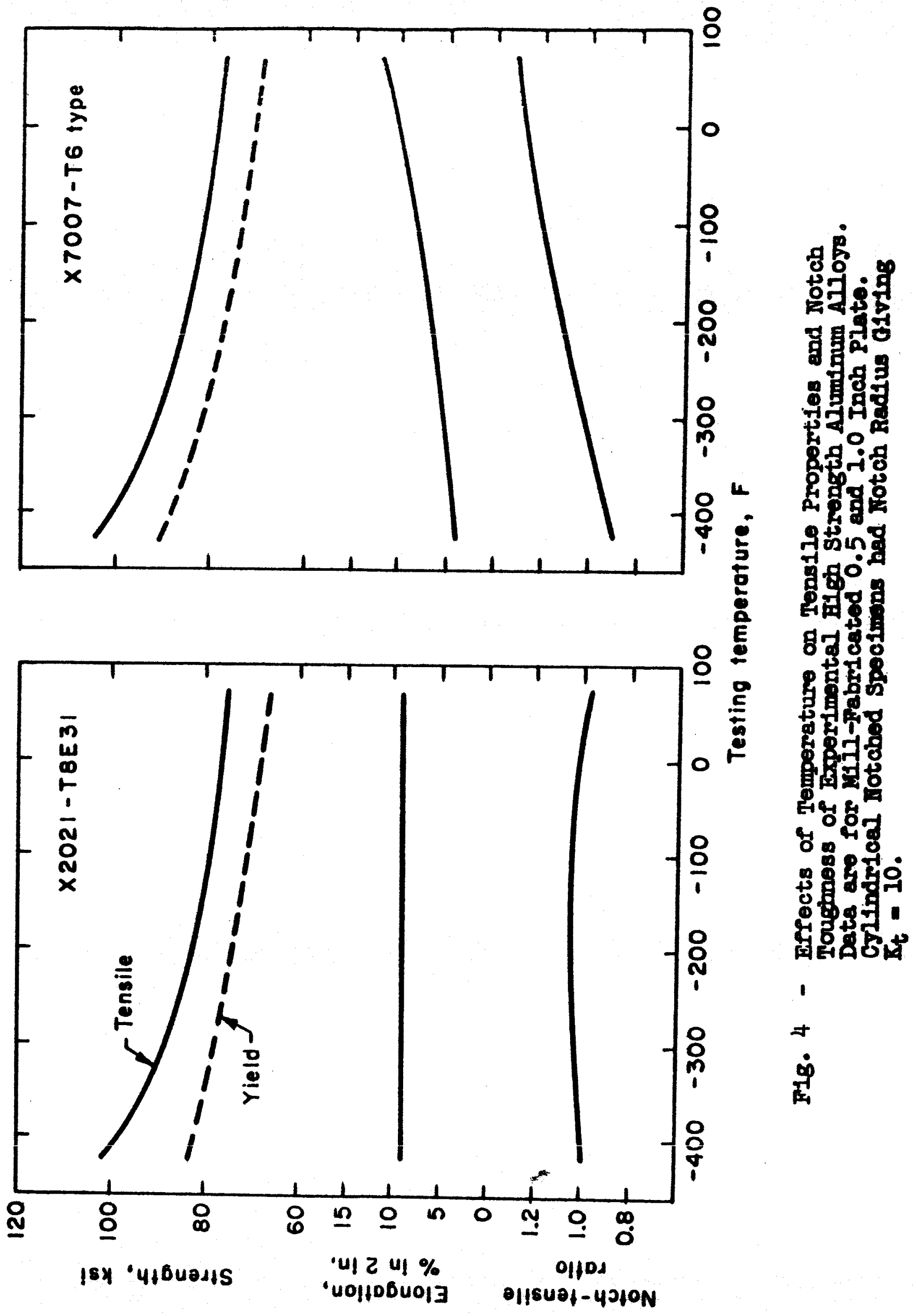




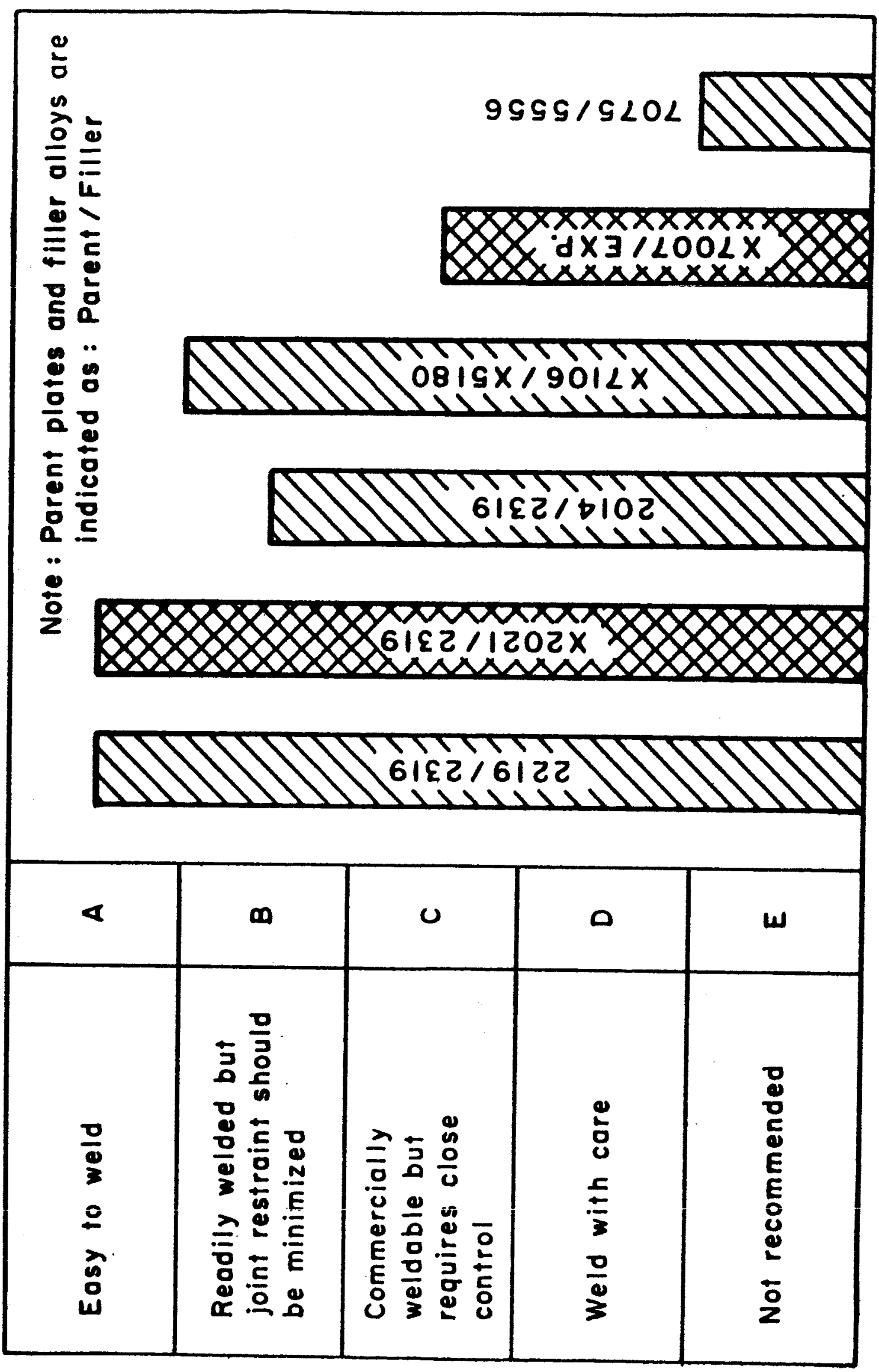

7
8
89
89
89
99






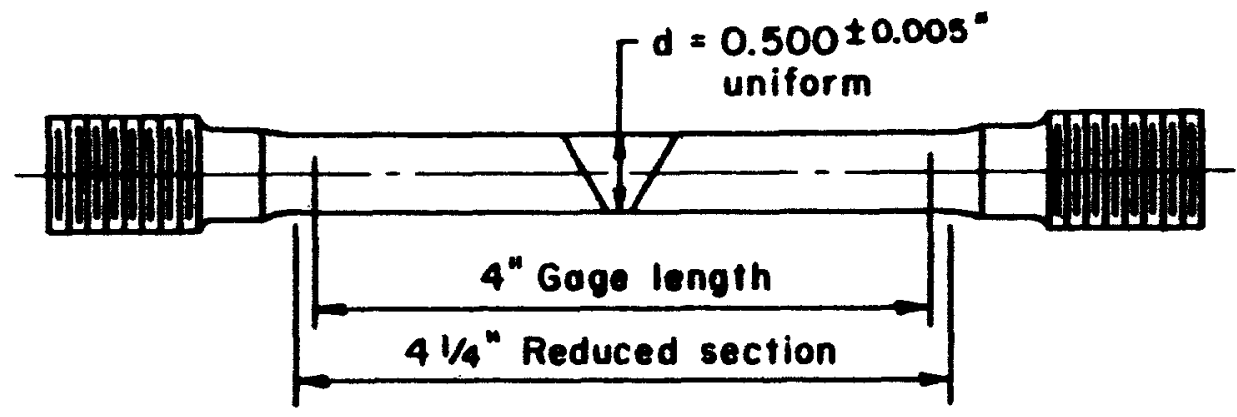

Reduced-section

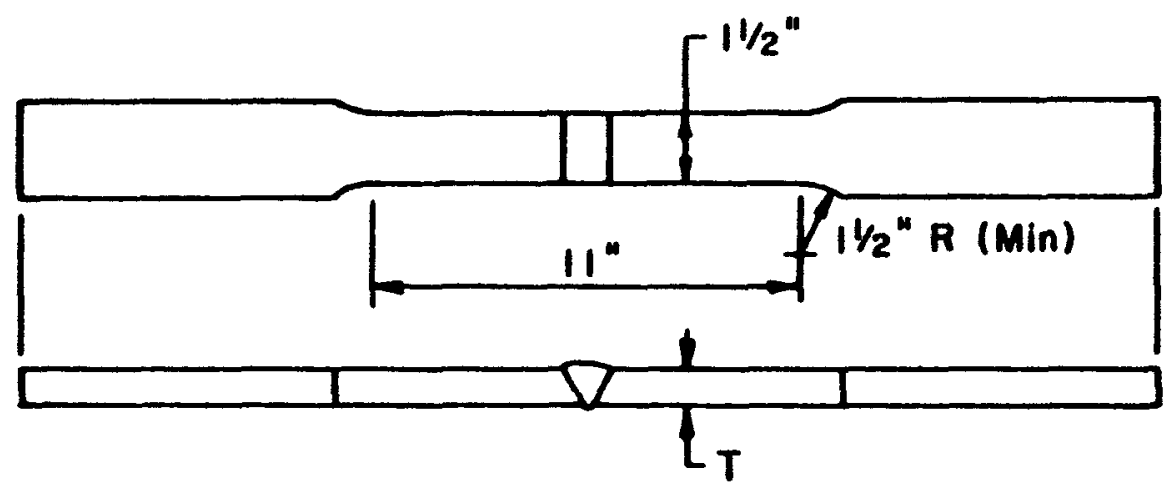

Full-section

F1g. 6 - Tensile Specimens from Groove-Welded Plate. 




